\title{
Biomechanical Evaluation of Segmental Pedicle Screw Fixation in Thoracolumbar Fracture: A Finite Element Study
}

\author{
Mina Alizadeh ${ }^{1,2 *}$ and Mohammed Rafiq Abdul Kadir ${ }^{1}$ \\ ${ }^{1}$ Department of Biomechanics \& Biomedical Materials, University Technology Malaysia, Malaysia \\ ${ }^{2}$ Spine Research Institute, The Ohio State University, USA
}

Submission: May 30, 2018; Published: July 12, 2018

*Corresponding author: Mina Alizadeh, Medical Implant Technology Group, Department of Biomechanics \& Biomedical Materials, University Technology Malaysia, 81310 Johor Bahru, Johor, Malaysia \& Spine Research Institute, The Ohio State University, 210 Baker Systems, 1971 Neil Avenue, Columbus, Ohio 43210 USA, Tel: +16787722108; Email: alizadeh.3@osu.edu

Abstract

Background: Transpedicular fixation is a common technique used to treat thoracolumbar burst fracture. However, the biomechanical effects of different configurations of pedicle screws and rod are lacking. Biomechanical analyses of thoracolumbar spine (T11-L3) rigidly fixed with transpedicular screw and rod across multiple spine levels was performed using finite element technique.

Method: The fixation constructs included eight pedicle screws (8PSLR), six pedicle screws (6PSMR) and four pedicle screws (4PSSR) with rods along with titanium mesh cage. Pure moment of $7.5 \mathrm{Nm}$ in three main planes (Sagittal, lateral and axial) was applied to simulate physiological motion of the lumbar spine. A $200 \mathrm{~N}$ compressive axial load was applied as preload correspond to the upper body weight.

Results: Range of motion, stress magnitude and distribution pattern within intervertebral discs and fixation structure were evaluated. Healthy thoracolumbar spine model was used as a base line for the comparison. The results suggest that increasing the number of pedicle screws causes a reduction in thoracolumbar range of motion. Intervertebral disc stresses were also found to be lower for constructs with higher number of pedicle screws. Shorter implant constructs experience higher amounts of stress in all directions of loading $(\mathrm{p}<0.001)$, increasing the possibility of metal fatigue.

Conclusion: The present study suggests that the use of longer segmental fixation for instable burst fracture provides well distributed stress to the implant while lowering the intervertebral disc stress, which consequently will increase fusion rate.

Keywords: Thoracolumbar burst fracture; Pedicle screw; Biomechanics; Orthopaedics; spine; Posterior rigid fixation

\section{Introduction}

Internal fixation is a common surgical technique used to stabilize thoracolumbar burst fractures [1]. This condition contributes to approximately $10-20 \%$ of all thoracolumbar spine fractures, which encompass $90 \%$ of all spine fractures [2-5]. Burst fracture is caused by compressive axial load on the vertebrae which results in the collapse of the corpus, it may cause spinal canal compression and spine instability [3,6]. Because of the inherent instability associated with burst fractures, generally it is preferred to fix spine rigidly to increase fusion rate as well as to provide stability [6-9].

Transpedicular screws are widely used in thoracolumbar spine fixations with the advantage of enhancing joint stability. This technique had shown a great effect on increasing fusion rate in biomechanical studies $[10,11]$. However, there appears to be very few reports demonstrating the most appropriate levels of fixation required to achieve stability following a single segment burst fracture. While a long segment fixation of the spine may provide more stability and consequently higher rate of fusion, the rigidity of the construct coupled with the immobilization of many spine segments will result in reduced range of motion $[3,12]$. It has also been reported that a rigid spinal implant may eventually result in the fatigue failure of implants [13]. In contrast, a short segment spinal constructs involving one level above and one level below the fracture have been shown to provide adequate stability whilst maintaining the flexibility of segments. However, high rates of failure including progressive kyphosis due to bent, broken and loosen screw as well as kyphosis due to continuous vertebral collapse without implant failure have been demonstrated in various reports [1,11,13-15]. Therefore, the aim of any internal fixation used for the stabilization of spinal fractures is not only to maintain 
its stability, but also renovation of anatomical geometry of the vertebra such as preserving vertebral height and restoration of sagittal alignment [9].

The purpose of this study was to perform a biomechanical comparison on the effect of different segmental posterior pedicle screw and rod (PSR) fixation in unstable thoracolumbar burst fracture using computational modeling. Since biomechanical investigation of various fixations performance demands comprehensive information about stress and strain distribution throughout the spine segment motion, finite element (FE) analysis was deemed most appropriate approach. Previous articles have proven the reliability of FE analyses for investigation purposes [16-25] and the technique was thus used for the present study.

\section{Materials and Methods}

Table 1: Material properties of FE model used in this study.

\begin{tabular}{|c|c|c|c|}
\hline Structure & $\begin{array}{l}\text { Constitutive } \\
\text { Model }\end{array}$ & $\begin{array}{l}\text { Young's Modulus } \\
\text { (MPa) }\end{array}$ & $\begin{array}{l}\text { Position } \\
\text { Ratio }\end{array}$ \\
\hline $\begin{array}{l}\text { Cancellous } \\
\text { bone }\end{array}$ & Neo-Hookean & $E=100$ & $\mathrm{v}=0.2$ \\
\hline \multirow{3}{*}{ Cortical bone } & \multirow{3}{*}{$\begin{array}{l}\text { Orthotropic } \\
\text { elastic }\end{array}$} & $\mathrm{E}_{1}=8000$ & $\mathrm{v}_{12}=0.4$ \\
\hline & & $\mathrm{E}_{2}=8000$ & $\mathrm{v}_{23}=0.3$ \\
\hline & & $E_{3}=12000$ & $\mathrm{v}_{31}=0.35$ \\
\hline $\begin{array}{l}\text { Posterior } \\
\text { elements }\end{array}$ & Neo-Hookean & $E=3500$ & $\mathrm{v}=0.3$ \\
\hline \multirow[t]{2}{*}{ Annulus } & Holmes-Mow & $E=1$ & $\mathrm{v}=0.4$ \\
\hline & & $\beta=3.4$ & \\
\hline Nucleus & Mooney-Rivlin & $C_{1}=0.12, C_{2}=0.03$ & \\
\hline Facet & Neo-Hookean & $E=30$ & $\mathrm{v}=0.4$ \\
\hline $\begin{array}{c}\text { Pedicle screws } \\
\text { and rod }\end{array}$ & & $E=110000$ & $\mathrm{v}=0.3$ \\
\hline $\begin{array}{l}\text { Titanium mesh } \\
\text { cage }\end{array}$ & & $E=110000$ & $\mathrm{v}=0.3$ \\
\hline
\end{tabular}

Various three-dimensional FE models (Table 1) were developed in this investigation including:

i. Intact human thoracolumbar spine (T11-L3),

ii. Fixed thoracolumbar spine with short segmental rods and pedicle screws with fusion cage,

iii. Fixed thoracolumbar spine with long segmental rods and pedicle screws with fusion cage,

iv. Fixed thoracolumbar spine with medium segmental rods and pedicle screws with fusion cage.

\section{Intact spine 3D Computational Model}

The geometrical representation of the model was obtained using thin slice $(1 \mathrm{~mm})$ CT images. The CT images of an entire spine column, from the cervical to the sacrum were acquired. Axial slices of CT images from the thoracic spine to the lumbar region (T11- L3) were imported into image processing software Amira 4.1 (Visage Imaging, United States) for segmentation using masking method. The geometrical construction was an important process within the finite element modeling, especially when evaluating a complex, multi component structure like spine. Therefore, during reconstruction process minimum smoothing were applied to maintain the natural geometry of bones.

Spinal soft tissues such as facet articulation and intervertebral disc (IVD) were not clearly detectable in CT images. Therefore, we attempt to reconstruct them geometrically in threedimensional modeling software SolidWorks (SolidWorks (2009), Dassault Systemes, USA). Intervertebral disc was modeled as a body consists of two parts, inner nucleus pulposus and outer annulus fibrosus (Figure 1). Reconstruction of facet articulation was done manually where the upper and lower surfaces of facet were extracted from adjacent vertebrae above and below the facet respectively and connected subsequently (Figure 2).

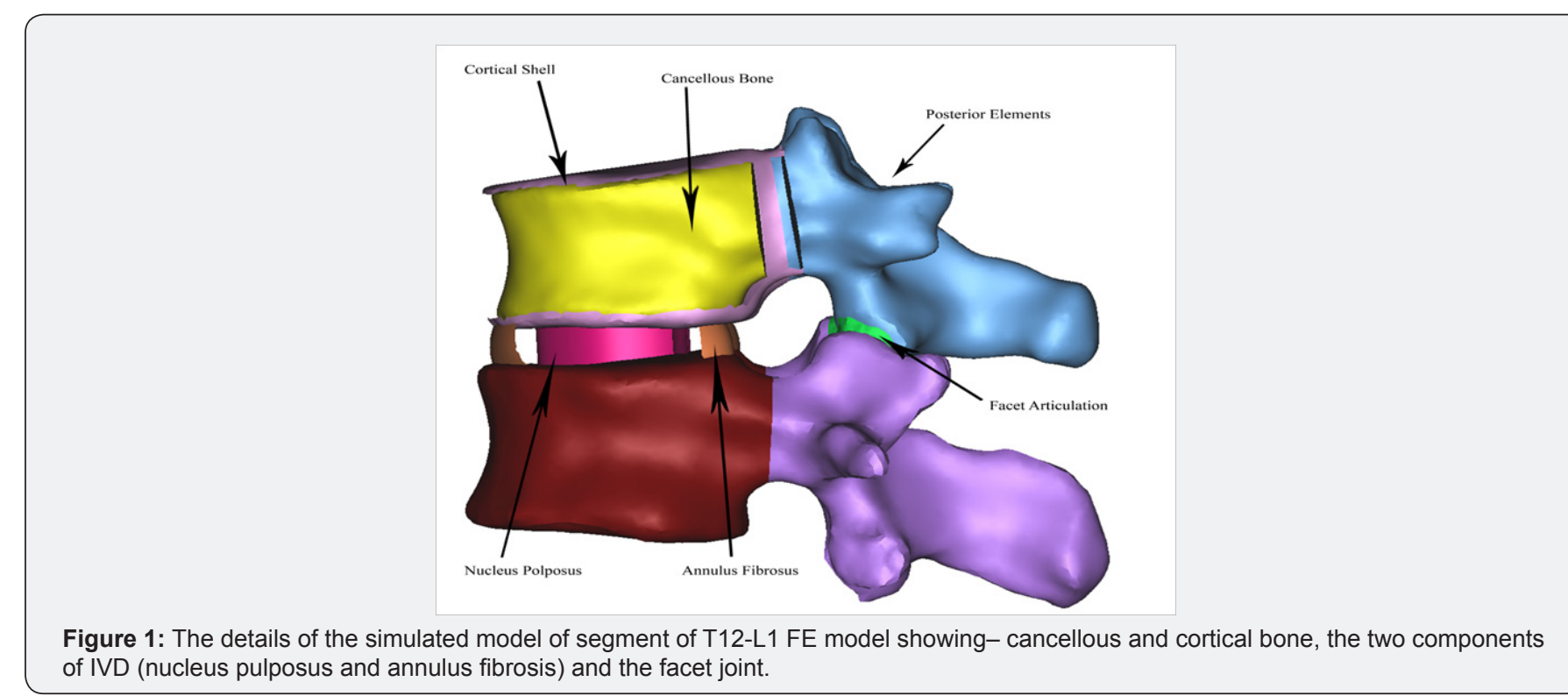




\section{Orthopedics and Rheumatology Open Access Journal (OROAJ)}

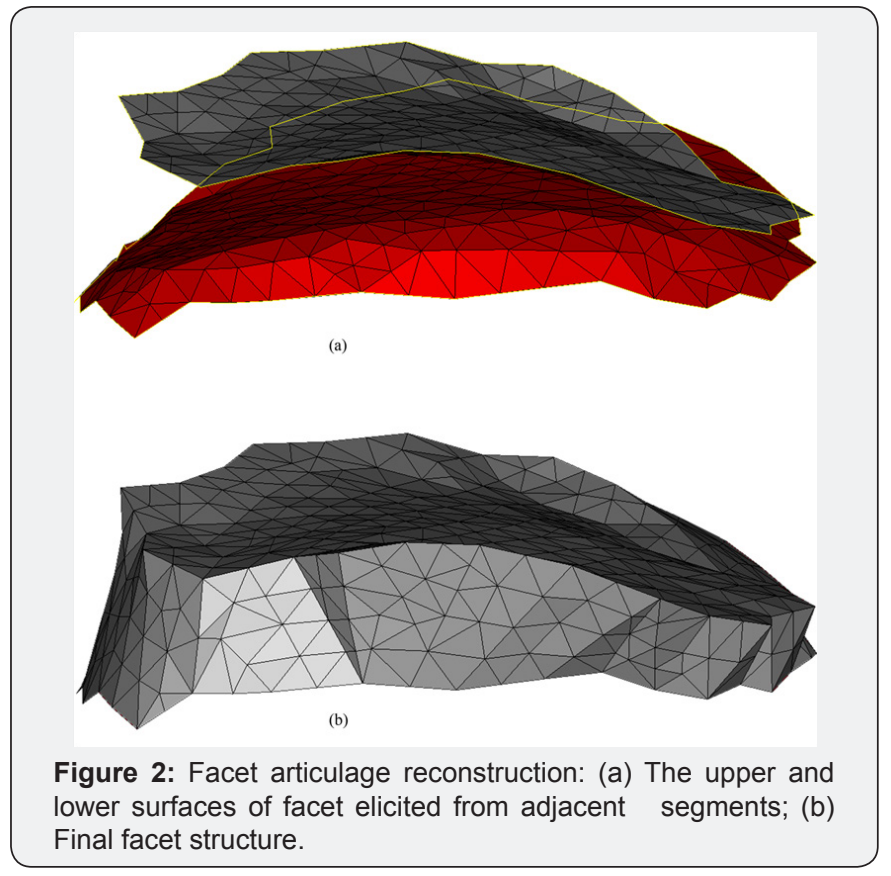

Constitutive models for every structure in the thoracolumbar spine were derived from previously published FE studies [2632]. An orthotropic elastic model was used to represent the cortical bone, while neo-Hookean model was used for cancellous bone and facet cartilage. Mooney-Rivlin was used to simulate the hyperelastic behavior of the nucleus pulposus as has been used in previous studies [32,33]. The annulus fibrosus was modeled as a matrix component using a compressible HolmesMow model. Seven spinal ligament group including anterior longitudinal ligament (ALL), posterior longitudinal ligament (PLL), intertransverse ligament (ITL) and capsular ligament (CL), ligamentum flavum (LF), interspinous ligament (ISL), supraspinous ligament (SSL) were simulated as non-linear tension-only spring elements characterized by displacementforce curve obtained from literature [26,27].

The entire 3D thoracolumbar spine model was adjusted precisely to achieve perfect contact surface before meshing with volume tetrahedral mesh. Additional checks were carried out on elements aspect ratio and cross elements to ensure the elements quality and consequently the finite element model (Figure 3).

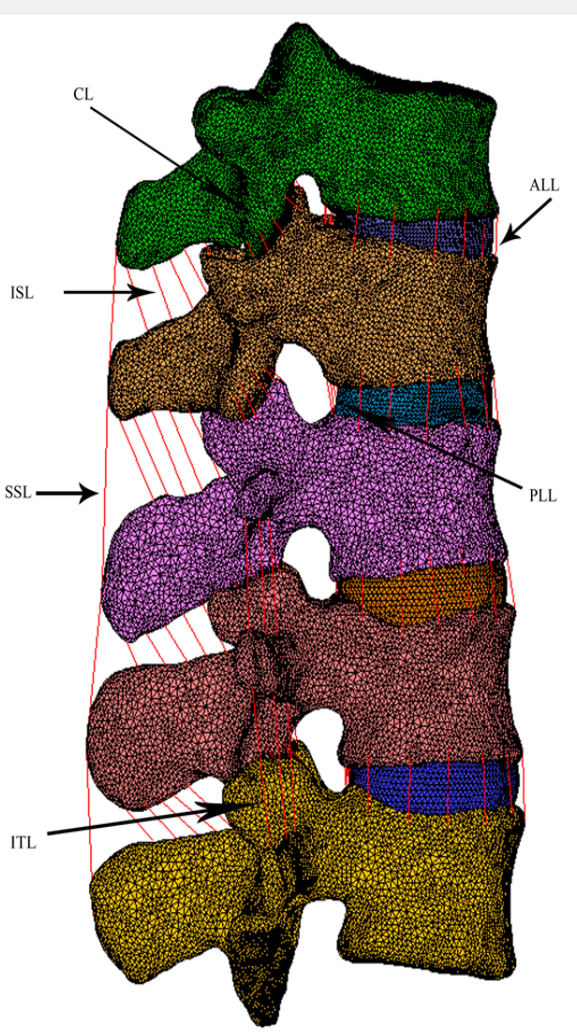

Figure 3: Major spinal ligaments used in the study for intact thoracolumbar spine: anterior longitudinal ligament (ALL), posterior longitudinal ligament (PLL), capsular ligament (CL), intertransvers ligament (ITL), interspinous ligament (ISL), supraspinous ligament (SSL).

\section{Fixed Spine 3D Computational Model}

The intact thoracolumbar spine was manipulated to simulate a burst fracture at L1. The worst case of burst fracture was applied in this study. Total corpectomy was performed on the injured level (L1) and vertebral body replacement was performed by placing a fusion cage, Figure 4. Anterior longitudinal ligament (ALL), posterior longitudinal ligament (PLL) and the whole IVD were removed to simulate real surgical environment. Spinal cord decompression by means of vertebral body replacement after complete corpectomy and spine stabilization with posterior pedicle screw based rigid fixation were also simulated. 
Three fixation methods were investigated:

i. Two-Level fixation (4PSSR) using four pedicle screws fixed one level above and one level below the injured segment supported with short length rods,

ii. Three-Level fixation (6PSMR) using six pedicle screws fixed one level above and two levels below the injured level supported with a medium length rod and

iii. Four-Level fixation (8PSLR) by eight pedicle screws embedded two levels up and two levels below fractured vertebra with long rod. The pedicle screws were in the appropriate position based on the advice of an experienced spine surgeon, Figure 4.

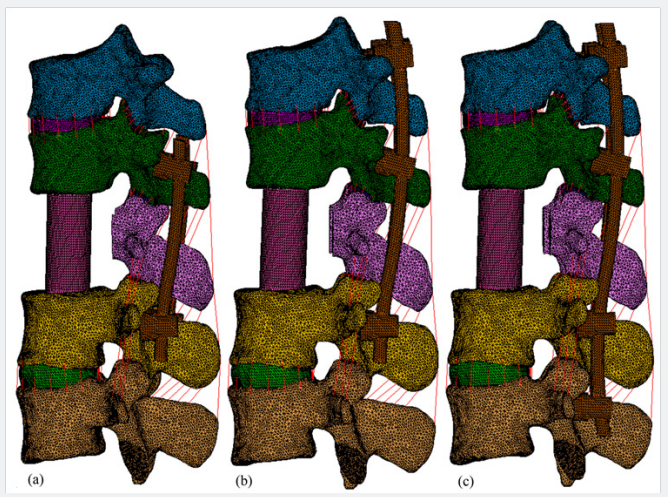

Figure 4: Complete finite element model of the fixed thoracolumbar spine: (a) short length rod with four pedicle screws (4PSSR) construct; (b) medium length rod with six pedicle screws (6PSMR) constructs; (c) long length rod with eight pedicle screws (8PSLR) system construct.

To minimize variability associated with implant structures during the computational process, consistent screw and titanium mesh cage geometry were employed for all the models. The length and outer diameter of the pedicle screws were 45 $\mathrm{mm}$ and $4.5 \mathrm{~mm}$ [34], respectively. Different length of titanium rods appropriate for the length of the fixation was applied in this simulation corresponding to the number of pedicle screws. However, the outer diameter of these rods remained the same at $6 \mathrm{~mm}$ [34]. The titanium mesh cage simulated in this study had a diameter of $19 \mathrm{~mm}$, and the holes featured on its surface were removed [6]. All pedicle screws and cage were assumed unthreaded to reduce FEM intricacy.

\section{Boundary and Loading Conditions}

In this thoracolumbar (T11-L3) model, the inferior surface of last segment was fixed at L3, which permitted free rotation in three principal axes but the translation in all three axes was constrained. Motion analyses were performed by applying similar load conditions which has been recommended for spine implants testing [35]. A pure moment of $7.5 \mathrm{Nm}$ was applied to the superior surface of T11 about the axis through the centre of the vertebral body in three motion planes to simulate three main physiological functions: flexion/extension, lateral bending (lef/right) and axial rotation (left/right) [31-33]. The fixed spine finite element model was preloaded using $200 \mathrm{~N}$ compression axial load which correspond to normal upper body weight $[34,36]$.

\section{Statistical Analysis}

Parametric test was used to determine mean differences and was applied where appropriate. Statistical significance was accepted at $\mathrm{p}<0.05$. Stastical analysis was carried out using statistical package SPSS (version 15.0).

\section{Results}

\section{Validation of the Intact Model}

Model validation was performed by measuring the range of motion (ROM) in the simulated spine and comparing the data to those obtained from previous reported studies [37-39]. The ROM of intact FE model under pure $7.5 \mathrm{Nm}$ moment in three main motion plains were used for comparison (Figure 5). Our FE analyses demonstrated good agreement of the present model to that of the experimental data.

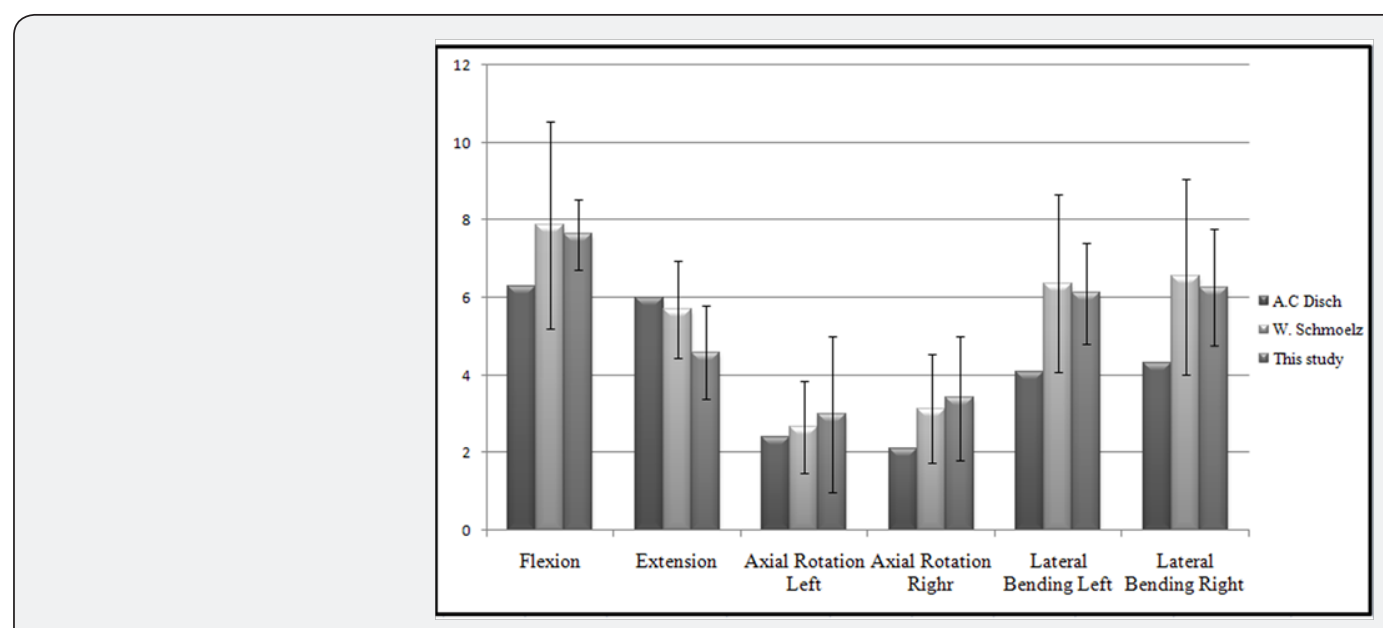

Figure 5: Range of motion (ROM) of thoracolumbar spine segment from this study compared to other experimental studies. 


\section{Orthopedics and Rheumatology Open Access Journal (OROAJ)}

\section{Motion Analyses of Fixed Spine}

The biomechanical effects of pedicle screw and rod (PSR) system with three various configurations of spine fixation on ROM were measured in all three motion planes. The data obtained is listed in Table 2 and the percentage ROM compared to the normal spine is shown in Figure 6. 8PSLR configuration was the stiffest construct with the lowest rotational displacement. The reduction in ROM for 8 PSLR was $94.5 \%, 85.2 \%, 64.2 \%$ and $76.0 \%$ over intact spine in flexion, extension, axial rotation and lateral bending, respectively. For 6PSMR the values were $84.7 \%$, $74.5 \%, 41.6 \%$ and $41.3 \%$. The lowest ROM reduction percentage was observed in 4PSSR system with values of $81.7 \%$ (flexion),
40.8\% (extension), 23.1\% (axial rotation) and 37.9\% (lateral bending).

Table 2: Range of motion in degree of fixed and normal (NS) thoracolumbar spine.

\begin{tabular}{|c|c|c|c|c|}
\hline & NS & 8PSLR & 6PSMR & PSSR \\
\hline Flexion & 7.63 & 0.42 & 1.17 & 1.4 \\
\hline Extension & 4.59 & 0.679 & 1.17 & 2.66 \\
\hline Lateral Bending (Left) & 6.12 & 1.33 & 2.89 & 3.43 \\
\hline Lateral Bending (Right) & 6.27 & 1.65 & 3.68 & 4.28 \\
\hline Axial Rotation (Left) & 3 & 1.1 & 1.7 & 2.3 \\
\hline Axial Rotation (Right) & 3.42 & 1.2 & 2 & 2.4 \\
\hline
\end{tabular}

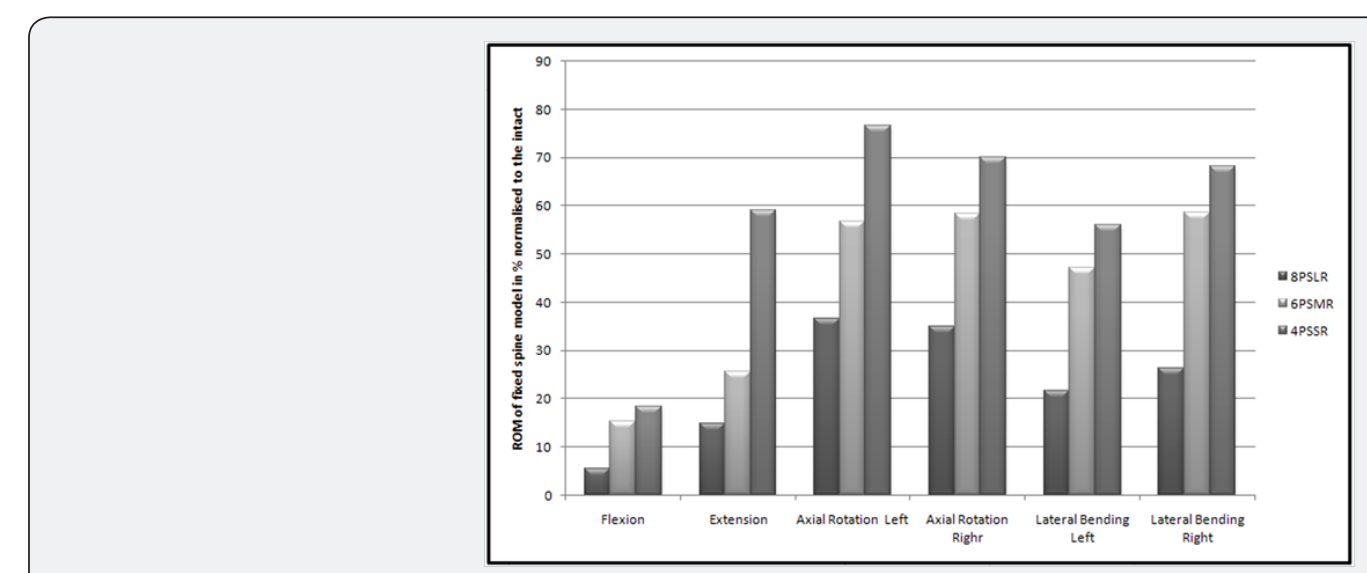

Figure 6: Normalized ROM of fused motion segments (T11-L3) to the normal (NS) for three fixation constructs: eight pedicle screws (8PSLR) system; six pedicle screws (6PSMR) constructs and four pedicle screws (4PSSR) construct.

\section{Von Mises Stress on IVD}

Average values of equivalent Von Mises stress on IVD at T11-T12 and L2-L3 in three different constructs are shown in Figure 7. In 8PSLR and 6PSMR configurations, the highest stress on the IVD was found in the two last vertebrae (L2-L3) while in the 4PSSR system, the highest stress was in T11-T12. It was demonstrated that lateral bending involved with highest Von Mises stress compared to other loading conditions. The contour map of Von Mises stress distribution on IVD between L2-L3 during lateral bending showed that this was the most critical disc due to maximum amount of shear stress (Figure 8). The average Von Mises stress on the IVD between L2 and L3 vertebra of 4PSSR, 6PSMR and 8PSLR was 511, 528 and $229 \mathrm{KPa}$, respectively. It is important to note that the mean stress value for 4PSSR and 6PSMR were similar for all simulated physiological loadings.

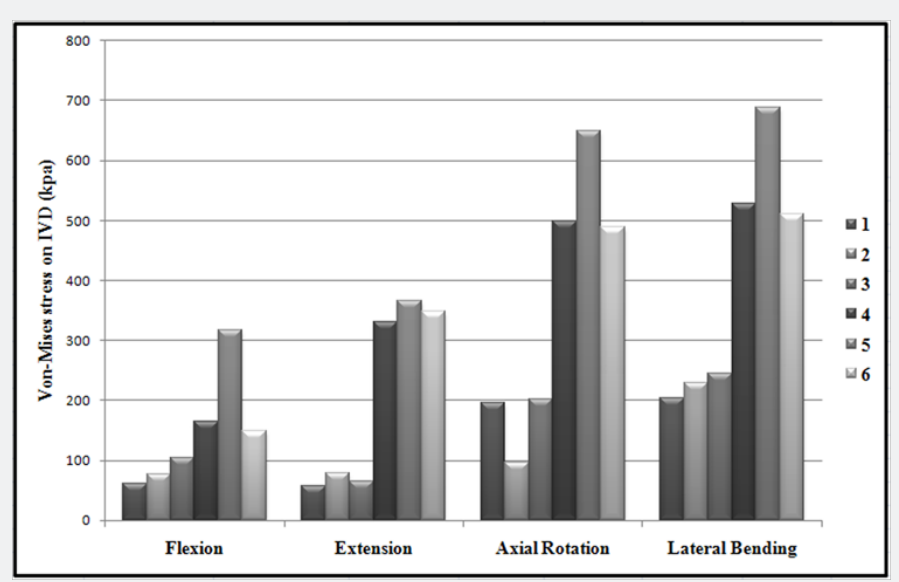

Figure 7: Average von Mises stress on the IVD in instrumented thoracolumbar between 1) T11-T12 with 8PSLR system; 2) L2-L3 with 8PSLR system; 3) T11-T12 with 6PSMR system; 4) L2-L3 with 6PSLR system; 5) T11-T12 with 4PSSR system and 6) L2-L3 with 4PSSR system. 


\section{Orthopedics and Rheumatology Open Access Journal (OROAJ)}

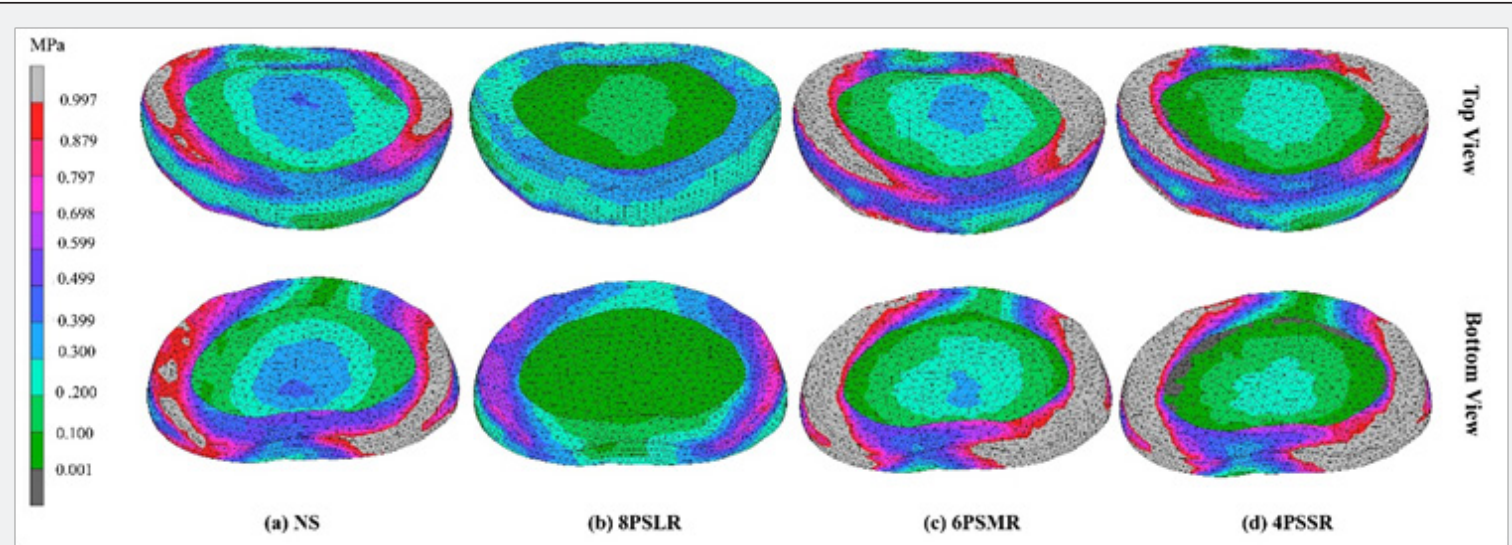

Figure 8: Von Mises stress distribution map in two side views under lateral bending moment for L2-L3 IVD: (a) normal spine (NS) model; (b) eight pedicle screw (8PSLR) structure; (c) six pedicle screws (6PSMR) structure; (d) four pedicle screws (4PSSR) structure.

\section{Von Mises Stress on Rods and Screws}

During flexion, stresses generated through the 8PSLR fixation system of pedicle screws and rods were significantly higher than that of 6PSMR and 4PSSR $(\mathrm{p}<0.01)$. Similarly during extension and lateral bending, 8PSLR construct demonstrated significantly higher stresses than 6PSMR and 4PSSR in sequence. However, this order of generated stress was not observed during axial rotation. In this simulation, 4PSSR generated significantly higher stress than 8PSLR and 6PSMR constructs respectively $(\mathrm{p}<0.01)$.

\section{Discussion}

The use of posterior instrumentation following a burst fracture involving the thoracolumbar region is well documented. This technique aims to restore spinal stability while protecting the spinal cord from further injury [3]. It is apparent that in many studies, the use of pedicle screws and rods are becoming increasingly common as this technique delineates the need for anterior approach hence reducing the likelihood of developing viscera injuries [40]. However, not all fracture configurations can be treated using rods and screws alone. The use of spinal cages is necessary to maintain vertebral height and provide the biomechanical stability required to support the function of the spine. In the present study, a total loss of the vertebral corpus was simulated to determine the maximal extend of the disease condition. This study conducted using a finite element method to analyze stress distribution of the instruments, i.e. pedicle screws and rods, as well as the adjacent intervertebral discs. The results of this study confirm that longer spine instrument construct is more likely to cause reduced range of motion but reduces the stresses within the adjacent intervertebral discs. The final choice of the length of a spinal construct, however, still needs to be justified clinically. The functional outcomes that need to be achieved in any clinical applications may differ between patients. Nevertheless, this study has provided some useful information which has not been addressed in previous studies:

a. while most reports have committed their work to focus only on the lumbar region, this study considers the thoracolumbar dynamics which clinically is the most mobile segment of the lower spine,

b. The present analyses involved the thoracolumbar region with four motion segments involving 5 vertebrae (T11-L3). Most of the previous studies on lumbar spine used a fewer motion segment with less vertebrae models,

c. this is, as far as the authors of this paper is aware, the only finite element model which uses a burst fracture modeled against the normal spine model.

In this study, the applied FE model geometry analog input was modeled against the conditions of a normal non-virtual human spine. This provided us with the ability to determine the limitations during rotational displacement following spinal fusion and, the influence of different PSS configurations. Besides, the probability of further disc injury because of high amounts of loading stress was also predicted within this model. However, some limitations were inherent in our FE model, which differ from others reported in the literature. Even though the nonlinear behavior was considered for the spinal ligaments, vertebral bodies was not simulated with sophisticated properties $[41,42]$. However, we are confident that such assumption didn't violate the reliability of our model as the results of this study showed good agreement with other published experimental work. The annulus fibrosis was modeled as Holmes-Mow matrix and the fluidic behavior of the nucleus pulposes was simplified with Mooney-Rivlin hyperelastic properties. This may result in inaccuracies of the data when translating the FE model results into practical applications. To circumvent this problem, the FEM analyses used in this study was validated against established normal spine models and more relevantly, to biomechanical models which have been validated in previous studies. In addition, a study had also shown that the cage may sink into the vertebral body over time as it is composed of mainly cancellous bone [43].

This invariably results in reduced vertebral body height, which in turn causes more strain to be generated into the 
implants. Ultimately, implants may fail causing severe morbidity to patients [3]. This scenario could not be simulated within the system, as there are inherent limitations present within the programming. Future designs may wish to incorporate these changes, thereby producing a good predictive model for further studies. More importantly, the mechanism described as distraction-compression principle, which involve the contraction of fibers namely the annulus fibrosis when the cage was inserted, was not modeled. This would have provided more accurate changes observed which would closely mimic clinical conditions.

Regardless of these limitations, the present study has shown that the developed spine model predicted the changes which would have been expected clinically and serve to be a useful model to determine conditions observed in burst fractures involving the thoracolumbar region. This would ultimately allow the simulation of spinal fractures using various fixation methods in this area to be done, providing better insight to the disease condition.

\section{Conclusion}

This study reports a three-dimensional finite element analysis which can predict the short term biomechanical postoperative effects of different PSR systems. It is shown that while a longer segment implant may provide better stress distribution thereby reducing the stress in the adjacent IVD, this results in reduced range of motion of the spine segments. As far as the authors of this paperis aware, this is the only FEM analyses/programming on the stability of the spinal construct for the treatment of thoracolumbar burst fracture. This could not have been achieved using mere biomechanics experiments and therefore serves as a more useful tool for future analyses wanting to determine the best treatment for this condition.

\section{Acknowledgement}

We would like to acknowledge the Malaysian Ministry of Science, Technology and Innovation for its research funding, and the Research Management Centre, University Technology Malaysia, for managing the research.

\section{Conflict of Interest}

None.

\section{References}

1. Sasso RC, Renkens K, Hanson D, et al. (2006) Unstable thoracolumbar burst fractures: anterior-only versus short-segment posterior fixation. J Spinal Disord Tech 19(4): 242-248.

2. Müller U, Berlemann U, Sledge J, Schwarzenbach O, et al. (1999) Treatment of thoracolumbar burst fractures without neurologic deficit by indirect reduction and posterior instrumentation: bisegmental stabilization with monosegmental fusion. Eur Spine J 8(4): 284-289.

3. Dai LY, Jiang SD, Wang XY, Jiang LS, et al. (2007) A review of the management of thoracolumbar burst fractures. Surg Neurol 67(3): 221-231.
4. Wood K, Buttermann G, Mehbod A, Garvey T, Jhanjee R, et al. (2003) Operative compared with nonoperative treatment of a thoracolumbar burst fracture without neurological deficit. A prospective, randomized study. J Bone Joint Surg Am 85-A(5): 773-781.

5. Denis F (1983) The three-column spine and its significance in the classification of acute thoracolumbar spinal injuries. Spine 8(8): 817831.

6. Zhang JW, Xiao BP, Xu RM, Zhao Liu jun, et al. (2009) Analysis of safety and effect of reconstructing anterior and middle columns by single posterior approach in treating lumbar burst fractures. Chin J Traumatol Zhonghua Chuang Shang Za Zhi 12(2): 107-112.

7. Denis F, Armstrong GW, Searls K, Matta L (1984) Acute thoracolumbar burst fractures in the absence of neurologic deficit. A comparison between operative and nonoperative treatment. Clin Orthop 189: 142-149.

8. Tezer M, Ozturk C, Aydogan M, Mirzanli C, Talu U, et al. (2005) Surgical outcome of thoracolumbar burst fractures with flexion-distraction injury of the posterior elements. Int Orthop 29: 347-350.

9. Behairy YM (2001) Unconventional fixation of thoracolumbar fractures using round hole bone plates and transpedicular screws. Ann Saudi Med 21(1-2): 30-34.

10. Markel DC, Graziano GP (1995) A comparison study of treatment of thoracolumbar fractures using the ace posterior segmental fixator and cotrel-dubousset instrumentation. Orthopedics 18(7): 679-686.

11. Carl AL, Tromanhauser SG, Roger DJ (1992) Pedicle screw instrumentation for thoracolumbar burst fractures and fracturedislocations. Spine 17(8): S317-324.

12. McBride GG (1993) Cotrel-Dubousset rods in surgical stabilization of spinal fractures. Spine 18: 466-473.

13. Xu HZ, Wang XY, Chi YL, Zhu QA, Lin Y, et al. (2006) Biomechanical evaluation of a dynamic pedicle screw fixation device. Clin Biomech Bristol Avon 21(4): 330-336.

14. McLain RF, Sparling E, Benson DR (1993) Early failure of short-segment pedicle instrumentation for thoracolumbar fractures. A preliminary report. J Bone Joint Surg Am 75(2): 162-167.

15. McNamara MJ, Stephens GC, Spengler DM (1992) Transpedicular short-segment fusions for treatment of lumbar burst fractures. J Spinal Disord 5(2): 183-187.

16.Abdul-Kadir MR, Hansen U, Klabunde R, Lucas D, Amis A (2008) Finite element modelling of primary hip stem stability: the effect of interference fit. J Biomech 41(3): 587-594.

17. Anderson AE, Ellis BJ, Maas SA, Weiss JA (2010) Effects of Idealized Joint Geometry on Finite Element Predictions of Cartilage Contact Stresses in the Hip. J Biomech 43: 1351-1357.

18. Janssen D, Mann KA, Verdonschot N (2008) Micro-mechanical modeling of the cement-bone interface: the effect of friction, morphology and material properties on the micromechanical response. J Biomech 41(15): 3158-3163.

19. Kayabasi O, Ekici B (2007) The effects of static, dynamic and fatigue behavior on three-dimensional shape optimization of hip prosthesis by finite element method. Mater Des 28: 2269-2277.

20. Teoh SH, Chan WH, Thampuran R (2002) An elasto-plastic finite element model for polyethylene wear in total hip arthroplasty. J Biomech 35(3): 323-330.

21. Bendjaballah MZ, Shirazi-Adl A, Zukor DJ (1997) Finite element analysis of human knee joint in varus-valgus. Clin Biomech Bristol Avon 12(3): 139-148. 
22. Boyd SK, Müller R, Zernicke RF (2002) Mechanical and architectural bone adaptation in early stage experimental osteoarthritis. J Bone Miner Res Off J Am Soc Bone Miner Res 17: 687-694.

23. Li G, Lopez O, Rubash H (2001) Variability of a three-dimensional finite element model constructed using magnetic resonance images of a knee for joint contact stress analysis. J Biomech Eng 123(4): 341-346.

24. Peña E, Calvo B, Martínez MA, Doblaré M (2006) A three-dimensional finite element analysis of the combined behavior of ligaments and menisci in the healthy human knee joint. J Biomech 39: 1686-1701.

25. Peña E, Calvo B, Martínez MA, Manuel Doblare (2007) Effect of the size and location of osteochondral defects in degenerative arthritis. A finite element simulation. Comput Biol Med 37(3): 376-387.

26. Rohlmann A, Zander T, Schmidt H, Wilke HJ, Bergmann G, et al. (2006) Analysis of the influence of disc degeneration on the mechanical behaviour of a lumbar motion segment using the finite element method. J Biomech 39(13): 2484-2490.

27. Ayturk UM, Puttlitz CM (2011) Parametric convergence sensitivity and validation of a finite element model of the human lumbar spine. Comput Methods Biomech Biomed Engin 14(8): 695-705.

28. Schmidt H, Galbusera F, Rohlmann A, Zander T, Wilke HJ (2012) Effect of multilevel lumbar disc arthroplasty on spine kinematics and facet joint loads in flexion and extension: a finite element analysis. Eur Spine J Off Publ Eur Spine Soc Eur Spinal Deform Soc Eur Sect Cerv Spine Res Soc 21(5): S663-S674.

29. Jacobs NT, Cortes DH, Peloquin JM, Vresilovic EJ, Elliott DM (2014) Validation and application of an intervertebral disc finite element model utilizing independently constructed tissue-level constitutive formulations that are nonlinear, anisotropic, and time-dependent. J Biomech 47(11): 2540-2546.

30. Zander T, Bergmann G, Rohlmann A (2009) Large sizes of vertebral body replacement do not reduce the contact pressure on adjacent vertebral bodies per se. Med Eng Phys 31(10): 1307-1312.

31. Schmidt H, Heuer F, Drumm J, Klezl Z, Claes L, et al. (2007) Application of a calibration method provides more realistic results for a finite element model of a lumbar spinal segment. Clin Biomech Bristol Avon 22(4): 377-384.

32. Schmidt H, Heuer F, Simon U, Kettler A, Rohlmann A, et al. (2006) Application of a new calibration method for a three-dimensional finite element model of a human lumbar annulus fibrosus. Clin Biomech Bristol Avon 21(4): 337-344.
33. Noailly J, Wilke HJ, Planell JA, Lacroix D (2007) How does the geometry affect the internal biomechanics of a lumbar spine bi-segment finite element model? Consequences on the validation process. J Biomech 40(11): 2414-2425.

34. Kim SM, Lim TJ, Paterno J, Kim DH (2004) A biomechanical comparison of supplementary posterior translaminar facet and transfacetopedicular screw fixation after anterior lumbar interbody fusion. J Neurosurg Spine 1(1): 101-107.

35. Eskander M, Brooks D, Ordway N, Dale E, Connolly P (2007) Analysis of pedicle and translaminar facet fixation in a multisegment interbody fusion model. Spine 32(7): E230-235

36. Beaubien BP, Derincek A, Lew WD, et al. (2005) In vitro, biomechanical comparison of an anterior lumbar interbody fusion with an anteriorly placed, low-profile lumbar plate and posteriorly placed pedicle screws or translaminar screws. Spine 30(16): 1846-1851.

37. Wilke HJ, Wenger K, Claes L (1998) Testing criteria for spinal implants: recommendations for the standardization of in vitro stability testing of spinal implants. Eur Spine J Off Publ Eur Spine Soc Eur Spinal Deform Soc Eur Sect Cerv Spine Res Soc 7(2): 148-154.

38. Phillips FM, Cunningham B, Carandang G, et al. (2004) Effect of supplemental translaminar facet screw fixation on the stability of stand-alone anterior lumbar interbody fusion cages under physiologic compressive preloads. Spine 29(6): 1731-1736.

39. Disch AC, Luzzati A, Melcher I, Schaser KD, Feraboli F, et al. (2007) Three-dimensional stiffness in a thoracolumbar en-bloc spondylectomy model: A biomechanical in vitro study. Clin Biomech 22(9): 957-964.

40. Schmoelz W, Schaser KD, Knop C, Blauth M, Disch AC (2010) Extent of corpectomy determines primary stability following isolated anterior reconstruction in a thoracolumbar fracture model. Clin Biomech 25(1): 16-20.

41. Zhong ZC, Wei SH, Wang JP, Feng CK, Chen CS, et al. (2006) Finite element analysis of the lumbar spine with a new cage using a topology optimization method. Med Eng Phys 28(1): 90-98.

42. Tschirhart CECE, Nagpurkar A, Whyne CMCM (2004) Effects of tumor location, shape and surface serration on burst fracture risk in the metastatic spine. J Biomech 37(5): 653-660.

43. Whyne CM, Hu SS, Lotz JC (2003) Burst fracture in the metastatically involved spine: development, validation, and parametric analysis of a three-dimensional poroelastic finite-element model. Spine 28(7): 652-660.

\section{Your next submission with Juniper Publishers will reach you the below assets}

- Quality Editorial service

- Swift Peer Review

- Reprints availability

- E-prints Service

- Manuscript Podcast for convenient understanding

- Global attainment for your research

- Manuscript accessibility in different formats

( Pdf, E-pub, Full Text, Audio)

- Unceasing customer service

Track the below URL for one-step submission

https://juniperpublishers.com/online-submission.php 